\title{
Insights into Knowledge, Attitude and Perception about Dental Ergonomics and Work-Related Musculo Skeletal Disorders (MSD) among Dental Professionals at Chengalpet District, Tamil Nadu, India: A cross-sectional study
}

\author{
Karthikayan $\mathrm{GR}^{1}$, Balaguhan $\mathbf{B}^{1}$, Mathanmohan $\mathrm{A}^{1}$, Deepak $\mathbf{V}^{1}$, Indrapriyadharshini $\mathrm{K}^{2}$, Nirmala \\ Devar $\mathbf{M}^{1}$
}

'Department of Oral \& Maxillo-Facial Surgery, Karpaga Vinayaga Institute of Dental Sciences, Tamil Nadu, India, ${ }^{2}$ Department of Public Health Dentistry, Karpaga Vinayaga Institute of Dental Sciences, Tamil Nadu, India.

\section{ABSTRACT}

Introduction: Despite all modern technological advances, dentistry is a profession still being affected by various musculoskeletal disorders, because of their prolonged working hours and difficult postures. Hence, this study was undertaken to assess the basic knowledge, attitude and practice of dental ergonomics during routine dental procedures among dental professionals and the second aim of the study focused on knowledge, attitude and practice of dental ergonomics by gender.

Methods: A cross-sectional study was conducted among 203 dental professionals from January 2021 to February 2021. A structured questionnaire consisting of 15 questions was administered. Descriptive analysis of demographic variables was done and knowledge, attitude and perception scores were performed using the chi-square test. Results: Among the 203 participants, a considerable majority of the participants which is about $75.9 \%$ (male: $71.1 \%$ and female: $79.6 \%$ ) reported that they have awareness of dental ergonomics. There were no statistically significant differences between males and females regarding knowledge score of $p=1.280$. About $46.4 \%$ of participants (male: $54.3 \%$ and female: $43.9 \%$ ), complained of neck pain followed by $44.3 \%$ (male $41.3 \%$ and female $45.2 \%$ ) complained of back pain. About $58.6 \%$ reported that the pain was caused strictly because of improper posture and non-ergonomically designed equipment. The difference between the gender variations was statistically significant regarding perception about dental ergonomics $\left(p=0.001^{*}\right)$

Conclusion: Dental professionals have considerable awareness of ergonomics in dental practice. The current study highlights the situation of ergonomics in dental practice in the form of knowledge, attitude, and practices.

Key words: Dental ergonomics, Dental professionals, Knowledge, Perception

DOI: https://doi.org/10.3126/ijosh.v12i1.41028

Conflicts of interest: None

Supporting agencies: None

Date of submission: 14.07.2021

Date of acceptance: 29.09.2021

Date of publication: 01.01.2022

\section{Corresponding Author}

\section{Dr G R Karthikeyan, M.D.S}

Associate Professor, Department of Oral and Maxillo-Facial Surgery,

Karpaga Vinayaga Institute of Dental Sciences,

GST Road, Chinnakolambakam, Palayanur (PO),

Chengalpattu (District), 603308, Tamil Nadu, India.

Phone: +919842177149

Email: grkomfs@gmail.com

ORCID: https://orcid.org/0000-0003-1387-8499

\section{INTRODUCTION}

n Greek, "Ergo" means work, and "Nomos" means natural laws or systems. Ergonomics, therefore, is an applied science concerned with designing products and procedures for maximum efficiency and safety at work. ${ }^{1}$

Ergonomics aims to find the best fit between the physical requirements of the work and the physical capacity of the worker. Ergonomics focuses on the nature of work, the armamentarium used for the work, and the

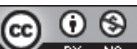

This journal is licensed under a Creative Commons AttributionNon Commercial 4.0 International License. 
entire working environment. In simple terminology, Ergonomics is a way to work smarter not harder, by designing tools, equipment, work stations and tasks to fit the job to the worker-NOT the worker to the job. Proper ergonomic design is imperative to prevent repetitive strain injuries and other musculoskeletal disorders, which can develop over time and can lead to long-term disability. ${ }^{2}$

The World Health Organization defines MSDs as "A disorder of the muscles, tendons, peripheral nerves or vascular system not directly resulting from an acute or instantaneous event (e.g., slips or falls). These disorders are considered to be work-related when the work environment and the performance of work contribute significantly but are only one of several factors contributing to the causation of multifactorial disease. . $^{3,4}$

Dentists are one of the highest potential risk professionals for MSDs. The long working hours, difficult postures and high visual demands make them susceptible to the development of MSDs. ${ }^{5}$ While performing a treatment; dentists should work meticulously, under conditions where access to the oral cavity is very arduous on an anxious patient which makes the dentist work in strenuous positions with tense muscles further progressing to the development of MSDs. ${ }^{6}$

Lietz et al. (2018) stated that the prevalence of musculoskeletal disease and pain among dental professionals (dentists, dental hygienists and dental students) vary from $10.8 \%$ to $97.9 \%$ and found that the neck is the most affected body region since $58.5 \%$ of dentists complained about neck pain in the last 12 months. The lower back represented the second most affected body region reported by $56.4 \%$ of dentists, followed by shoulder pain (43.1\%) and pain in the upper back $(41.1 \%) .{ }^{7}$ MSDs in dentistry can cause reduced productivity and even early retirement. ${ }^{8}$ Ergonomics in dentistry when followed accordingly, make a certain reduction in the prevalence of MSDs among dental professionals thereby improving efficiency, with better quality and greater comfort for both the practitioners and patients. 9,10 Dental profession is the one where many work-related disorders affect many of the clinicians. In the dental profession, these problems are due to the repetitive movements within the small place and also long-standing exertion of forces during dental procedures. ${ }^{11}$ Musculoskeletal pain is a major problem among dental personnel that affects efficiency and job satisfaction; the prime reason for this may be attributed to inappropriate workplace ergonomics. In the Indian context where the numbers of practicing dentists are steadily increasing, there is a continued increase in the prevalence of musculoskeletal problems. ${ }^{12}$ Research studies highlight a higher prevalence of work-related MSDs among dental professionals and dental students. The nature of their work might result in MSDs in many parts of the body depending on the location and the type of work they perform. ${ }^{13}$ Thus, dentists need proper knowledge about the principles of dental ergonomics to apply them in their clinical practice to protect themselves from Work-related MSD.

In the Indian setup, there is a severe dearth of literature evaluating knowledge, awareness, and practices among dental professionals regarding optimal postures at the time of rendering oral health services. Hence, this study was undertaken to assess the basic knowledge, attitude and practice of dental ergonomics during routine dental procedures among dental professionals and the second aim of the study focused on gender differences in knowledge, attitude and practice of dental ergonomics.

\section{METHODS}

A cross-sectional survey was conducted to assess the knowledge, attitude and practice about dental ergonomics and work-related MSDs, among dental professionals in Chengalpet district, Tamilnadu, India from January 2021 to February 2021. The study design was based on the guidelines of the Strengthening the Reporting of Observational Studies in Epidemiology (STROBE initiative). The study protocol was approved by the Institutional Ethics Committee [IEC/KIDS/022021/027], Karpaga Vinayaka Institute of Dental Sciences, Chengalpet, Tamilnadu before the start of the study. The objective of the study was explained and written informed consent was obtained from all the participants. A pilot study was conducted among 25 dental practitioners to estimate the sample size and to check the feasibility of the study. The sample size was calculated with $80 \%$ statistical power, $\alpha=0.05$, $95 \%$ confidence interval, $10 \%$ margin of error $(E)$ and knowledge regarding dental ergonomics $(67 \%)^{6}$, using Gpower software (Version 3.1.9.7). The sample size was estimated to be about 200 participants, which included postgraduates, staff attending the institution and private practitioners. The nursing staff and the dental auxiliaries and those who refused to give consent were excluded from the study. A convenience 
sample of 203 dental professionals who fulfilled the above-mentioned criteria was included in the study.

A self-structured questionnaire to elicit knowledge, attitude, practice and self-perception regarding dental ergonomics and work-related MSDs was developed based on the previous literature. The questionnaire encloses four domains, consisting of a total of 15 questions (closed-ended and multiple-choice questions) with 3 questions on knowledge, 3 questions on attitude, 3 questions on practice and 6 questions assessing perception which focus on ergonomic principles while treating patients in clinical practice.

Before the start of the study, the questionnaire was tested for content validity by five Panelists. The questionnaire was assessed for Content Validity Index (CVI) relevance with simplicity, clarity, ambiguity and objectivity were checked and the CVI score is 0.73 . Cronbach a values for knowledge, attitude, practice and self-perception were $0.684,0.784,0.81$ and 0.810 respectively by test-retest design which indicated a significant correlation. The questionnaire was given to the same persons twice two days apart. The pilot study participants did not take part in the main study.

A single trained investigator collected the data. The participants were given a brief explanation about the study and the participation was voluntary and self-administrative. The research instrument used in the study was the proprietary questionnaire and was completed by the respondents. The additional items to ascertain demographic data on participant's gender, age were also collected and confidentiality and anonymity of the participants were assured.

The data were initially compiled in a Microsoft Excel spreadsheet, the data analysis was done with the Statistical Package for the Social Sciences for Windows version 20.0 software (IBM, Chicago Inc., IL, USA; 2012). Descriptive statistics were performed for demographic variables. Inferential statistics were done with the Chi-square test and for all analyses, $p<0.05$ was considered statistically significant.

\section{RESULTS}

The present study was conducted to assess the knowledge, attitude, practice and perception about dental ergonomics and work-related MSDs, among dental professionals in Chengalpet district, Tamilnadu, India. Among 203 study participants, 22.6\% ( $n=46$ ) were males and $77.33 \%(n=157)$ were females. The mean age of the study subjects was found to be $35.07 \pm 4.17$ years. The response rate to the questionnaire was $100 \%$.

Table 1 describes the distribution based on knowledge scores of dental ergonomics and work-related MSDs among the study participants. Among the total participants, a considerable majority of the participants which is about $75.9 \%$ (male: $71.1 \%$ and female: $79.6 \%$ ) reported that they have awareness of dental ergonomics. Of the study participants, $75.4 \%$ (male: $82.6 \%$ and female: $73.2 \%$ ) heard the word "Ergonomics", before selecting dentistry as their profession. The vast majority of participants around $60.1 \%$ (male: $52.2 \%$ and female: $60.1 \%$ ) were found to have good awareness about Musculo Skeletal Disorders (MSDs) related to dentistry. In all the three questions concerning the knowledge about dental ergonomics and MSDs, there was no statistically significant difference $(p=1.280, p=1.679, p=1.558$ respectively) found between males and females.

Table 2 represents the distribution of attitude scores of dental ergonomics and work-related MSDs according to gender. Among the total participants, $71.4 \%$ (male $71.7 \%$ and female $71.3 \%$ ) were taught about the principles of ergonomics during their third or final year of study. Out of all participants, $68.9 \%$ (male: $63 \%$ and female: $70.7 \%$ ) answered that they knew about the role and principles of Dental ergonomics in their practice. The majority of the participants $(87.2 \%)$, male: $80.4 \%$ and female: $89.2 \%$, responded that they had followed the ergonomic principles while setting up their dental clinic. The second part of this questionnaire with three questions intended to assess the attitude about dental ergonomics had no statistically significant difference ( $p=0.132, p=0.975, p=2.432$ respectively) found between the male and female participants.

Table 3 describes the distribution of the participants towards practice. Of the total participants, more than 91.6\% (male: $93.5 \%$ and female: $91.1 \%$ ) thought that practicing dentistry without following dental ergonomics led to work-related MSDs. Of the study participants, 9.8\% (male: $10.9 \%$ and female: $9.6 \%$ ) practiced dentistry by sitting, $4.9 \%$ (male: $6.5 \%$ and female: $4.5 \%$ ) by standing and $85.2 \%$ (male: $82.6 \%$ and female: $86 \%$ ) by both sitting and standing position. Among the dental professionals, the principles of operator's position, patient's position and dental chair's position were followed to some extent by $71.4 \%$ (male: $82.6 \%$ and female: $68.2 \%$ ) and properly by $27.2 \%$ 
(male: $15.2 \%$ and female: $30.6 \%$ ) in their practice. There was no statistically significant difference in the score regarding practice between males and females.

Among the participants, $83.2 \%$ (male: $80.4 \%$ and female: $84.1 \%$ ) have pain regularly; $8.4 \%$ (male: $4.3 \%$ and female: $10.8 \%$ ) have pain to some extent and $8.4 \%$ (male: $19.6 \%$ and female: $5.1 \%$ ) never had pain during their practice. About $94.6 \%$ (male: $93.5 \%$ and female: $94.9 \%$ ) participants had pain for the first time during their BDS course itself. Of those, $46.4 \%$ (male: $54.3 \%$ and female: $43.9 \%$ ) complained of neck pain followed by $44.3 \%$ (male: $41.3 \%$ and female: $45.2 \%$ ) who complained of back pain. More than half $[58.6 \%$ (male: $43.5 \%$ and female: $63.1 \%$ )] reported that the pain was caused strictly because of improper posture and non-ergonomically designed equipment. Out of 203 participants, only $4.9 \%$ (male: $15.2 \%$ and female: $1.9 \%$ ) were doing exercise or yoga regularly; 47.3\% (male: $39.1 \%$ and female: $49.7 \%$ ) were doing rarely and $47.8 \%$ (male: $45.7 \%$ and female: $48.4 \%$ ) never performed exercise to combat MSDs. Of the participants, only $7.9 \%$ (male: $41.3 \%$ and female: $45.2 \%$ ) were getting medical advice, $10.8 \%$ (male: $4.3 \%$ and female: $8.9 \%$ ) were seeking internet and 81.3\% (male: $73.9 \%$ and female: $83.4 \%$ ) had never consulted anywhere, if they have MSDs [Table 4]. Concerning the perception domain, the difference between the gender variations was statistically significant for all the questions.

Table 1: Distribution of knowledge about Dental ergonomics \& work-related MSD among dental professionals according to gender $(n=203)$

\begin{tabular}{|c|c|c|c|c|}
\hline Knowledge about & $\begin{array}{l}\text { Male } \\
\mathrm{n}(\%)\end{array}$ & $\begin{array}{l}\text { Female } \\
\mathrm{n}(\%)\end{array}$ & $\begin{array}{l}\text { Total } \\
\mathrm{n}(\%)\end{array}$ & $p$ value \\
\hline Awareness of "Ergonomics" in dentistry & $33(71.7 \%)$ & $125(79.6 \%)$ & $158(77.8 \%)$ & 1.280 \\
\hline $\begin{array}{l}\text { Heard the word "Ergonomics" before entering in to dental } \\
\text { profession. }\end{array}$ & $38(82.6 \%)$ & $115(73.2 \%)$ & $153(75.4 \%)$ & 1.679 \\
\hline $\begin{array}{l}\text { Aware of musculo skeletal disorders(MSDs) related to } \\
\text { dentistry. }\end{array}$ & $24(52.2 \%)$ & $98(62.4 \%)$ & $122(60.1 \%)$ & 1.558 \\
\hline
\end{tabular}

* Significance level at $p \leq 0.05$,

Table 2: Distribution of attitude about Dental ergonomics \& work-related MSD among dental professionals according to gender $(n=203)$

\begin{tabular}{lcccc}
\hline Attitude about Dental Ergonomics & Male $\mathbf{n}(\%)$ & Femalen(\%) & Total $\mathbf{n}(\%)$ & $\boldsymbol{p}$ value \\
\hline $\begin{array}{l}\text { Ergonomics principle was taught during } \\
\text { third/final year }\end{array}$ & $33(71.7 \%)$ & $112(71.3 \%)$ & $145(71.4 \%)$ & 0.132 \\
$\begin{array}{l}\text { Know about the role of Dental ergonomics } \\
\text { principle in your practice }\end{array}$ & $29(63 \%)$ & $111(70.7 \%)$ & $140(68.9 \%)$ & 0.975 \\
$\begin{array}{l}\text { Consider the ergonomic principles during } \\
\text { setup of dental office. }\end{array}$ & $37(80.4 \%)$ & $140(89.2 \%)$ & $177(87.2 \%)$ & 2.432 \\
\hline
\end{tabular}

* Significance level at $p \leq 0.05$.

Table 3: Distribution of dental professionals towards practicing Dental ergonomics according to gender $(n=203)$

\begin{tabular}{|c|c|c|c|c|c|}
\hline Practicing Dental Ergonomics & Options & $\begin{array}{l}\text { Male } \\
\text { n (\%) }\end{array}$ & $\begin{array}{c}\text { Female } \\
\text { n (\%) }\end{array}$ & $\begin{array}{l}\text { Total } \\
\text { n (\%) }\end{array}$ & $p$ value \\
\hline \multirow{2}{*}{$\begin{array}{l}\text { Practicing dentistry without Dental } \\
\text { ergonomic principle can cause MSDs }\end{array}$} & Yes & $43(93.5 \%)$ & $143(91.1 \%)$ & $186(91.6 \%)$ & \multirow{2}{*}{0.60} \\
\hline & No & $3(6.5 \%)$ & $14(8.9 \%)$ & $17(8.4 \%)$ & \\
\hline \multirow{3}{*}{ Kind of dentistry you practice } & Standing & $3(6.5 \%)$ & $7(4.5 \%)$ & $10(4.9 \%)$ & \multirow{3}{*}{0.812} \\
\hline & Sitting & $5(10.9 \%)$ & $15(9.6 \%)$ & $20(9.8 \%)$ & \\
\hline & Both & $38(82.6 \%)$ & $135(86 \%)$ & $173(85.2 \%)$ & \\
\hline \multirow{3}{*}{$\begin{array}{l}\text { Properly follow the principles of operator's } \\
\text { position, patient position and dental chair } \\
\text { position for treating the patients in dental } \\
\text { office }\end{array}$} & Yes properly & $7(15.2 \%)$ & $48(30.6 \%)$ & $55(27.2 \%)$ & \multirow{3}{*}{0.115} \\
\hline & To some extent & $38(82.6 \%)$ & $107(68.2 \%)$ & $145(71.4 \%)$ & \\
\hline & No & $1(2.2 \%)$ & $2(1.3 \%)$ & $3(1.4 \%)$ & \\
\hline
\end{tabular}

* Significance level at $p \leq 0.05$ 
Table 4: Distribution of dental professionals towards self-perception about work-related MSD based on gender $(n=203)$

\begin{tabular}{|c|c|c|c|c|c|}
\hline Self- perception of MSDs & Options & $\begin{array}{l}\text { Male } \\
\mathrm{n}(\%)\end{array}$ & $\begin{array}{c}\text { Female } \\
\text { n (\%) }\end{array}$ & $\begin{array}{l}\text { Total } \\
\text { n (\%) }\end{array}$ & $p$ value \\
\hline \multirow{3}{*}{ Pain while practicing } & Regularly & $37(80.4 \%)$ & $132(84.1 \%)$ & $169(83.2 \%)$ & \multirow{3}{*}{$0.001^{*}$} \\
\hline & To some extent & $2(4.3 \%)$ & $15(10.8 \%)$ & $17(8.4 \%)$ & \\
\hline & Never & $9(19.6 \%)$ & $8(5.1 \%)$ & $17(8.4 \%)$ & \\
\hline \multirow{3}{*}{ Musculoskeletal pain for first time } & During BDS course & $43(93.5 \%)$ & $149(94.9 \%)$ & $192(94.6 \%)$ & \multirow{3}{*}{$0.023^{*}$} \\
\hline & Before joining BDS & $1(2.2 \%)$ & $8(5.1 \%)$ & $9(4.3 \%)$ & \\
\hline & After passing out & $2(4.3 \%)$ & $1(0.2 \%)$ & $2(0.1 \%)$ & \\
\hline \multirow{4}{*}{ Most common location for pain } & Lower back & $19(41.3 \%)$ & $71(45.2 \%)$ & $90(44.3 \%)$ & \multirow{4}{*}{$0.041^{*}$} \\
\hline & Neck & $25(54.3 \%)$ & $69(43.9 \%)$ & $94(46.4 \%)$ & \\
\hline & Thoracic & $1(2.2 \%)$ & $7(4.5 \%)$ & $8(3.9 \%)$ & \\
\hline & Extremities & $1(2.2 \%)$ & $10(6.4 \%)$ & $11(5.4 \%)$ & \\
\hline \multirow{3}{*}{$\begin{array}{l}\text { Back pain is because of improper } \\
\text { posture and non-ergonomically } \\
\text { designed equipment }\end{array}$} & Yes strictly & $20(43.5 \%)$ & $99(63.1 \%)$ & $119(58.6 \%)$ & \multirow{3}{*}{$0.035^{*}$} \\
\hline & To some extent & $11(23.9 \%)$ & $31(19.7 \%)$ & $42(20.7 \%)$ & \\
\hline & I don't know & $15(32.6 \%)$ & $27(17.2 \%)$ & $42(20.7 \%)$ & \\
\hline \multirow{3}{*}{$\begin{array}{l}\text { Do regular exercise or Yoga to } \\
\text { combat / prevent MSDs }\end{array}$} & Regularly & $7(15.2 \%)$ & $3(1.9 \%)$ & $10(4.9 \%)$ & \multirow{3}{*}{$0.001^{*}$} \\
\hline & Sometime & $18(39.1 \%)$ & $78(49.7 \%)$ & $96(47.3 \%)$ & \\
\hline & Never & $21(45.7 \%)$ & $76(48.4 \%)$ & $97(47.8 \%)$ & \\
\hline \multirow{3}{*}{$\begin{array}{l}\text { Taken the medical advice for } \\
\text { Musculoskeletal disorders from }\end{array}$} & Consulted physician & $2(4.3 \%)$ & $14(8.9 \%)$ & $16(7.9 \%)$ & \multirow{3}{*}{$0.020^{*}$} \\
\hline & Internet & $10(21.7 \%)$ & $12(7.6 \%)$ & $22(10.8 \%)$ & \\
\hline & Never & $34(73.9 \%)$ & $131(83.4 \%)$ & $165(81.3 \%)$ & \\
\hline
\end{tabular}

* Significance level at $p \leq 0.05$.

\section{DISCUSSION}

This study showed that knowledge scores were $72 \%$, which was similar to a study conducted by Garbin et al. ${ }^{14}$ The results of the present study showed no significant difference in the knowledge score between males and females. However, female dentists possess better dental ergonomics knowledge than males. This might be because they are more prone to have workrelated MSDs than males, so they get more interest to learn about dental ergonomics. ${ }^{15}$

The level of attitude found in the current study is $71.4 \%$ which was similar to results found in a study conducted by Kalghatgi $S$ et al. ${ }^{12}$ There was no statistically significant difference found between male and female dentists. This illustrates that this is a good reflection of acceptability and willingness to adopt the ergonomic principles in routine dental practice by the study participants.

There was no statistically significant difference found between male and female dentists. The probable reason for a high positive attitude towards ergonomics among dental practitioners could be the likelihood of being affected by various musculoskeletal disorders during undergraduate clinical working periods. ${ }^{12}$

The most prevalent regions for pain in dentists were the neck followed by the shoulder. Female dentists reported neck pain $\left(p=0.041^{*}\right)$ significantly more often in all evaluated periods than male dentists in the current study. Our findings are in line with the results of previous studies showing that neck, shoulder and lower back pain were commonly reported among dentists. This is contrary to the study conducted by Almosa NA et al, who found that back pain has been reported to be the most common work-related MSDs among dentists, followed by neck pain. ${ }^{16}$ Several studies have shown that physical strain endured by dental professionals during dispensing the dental treatment can lead to work-related MSDs. ${ }^{12}$ The risk of development of WRMSDs is higher among dental professionals as the work demands good vision, use of excessive force, and commence accurate repetitive hand and wrist movements while sitting in a static or awkward posture. ${ }^{17}$ Similarly, bending and twisting of the neck by the dentists during treatment of patients have also been reported to be related to discomfort 
and pain in the cervical, thoracic and lumbar regions of the spine.${ }^{18}$ Additionally, the female musculoskeletal system can exert only two-thirds of the force than the male system can; therefore, it is more difficult for women to stabilize their bodies and compensate for the physical strain linked to providing dental care. ${ }^{19}$

In the present study, about $94.6 \%$ of the participants reported that they had musculoskeletal pain for the first time during the BDS course. Morse et al, also reported a higher prevalence of WRMSDs symptoms among dental students ever since they began their practical work in university clinics. ${ }^{20}$ This could be due to change in the work nature, practice pattern and working hours from non-clinical years. Continuing education about correct posture while handling patients as well as practicing ergonomic skills and incorporating them into the undergraduate curriculum, would be beneficial for dental students to relieve from MSDs. ${ }^{21}$

Regarding exercise habits, the findings revealed that almost half of the dentists $(47.8 \%)$ did not exercise at all and $10 \%$ of them exercised regularly. This was similar to the findings by Hanefioglu $\mathrm{M}$ et al. ${ }^{22}$ Our study points to the fact that routine exercise can decrease their pain. If dentists do not pay attention to their posture, work-related MSDs and early retirement are inevitable.

About $58.6 \%$ of all participants reported that back pain is because of improper posture and non-ergonomically designed equipment. There was a statistically significant difference between male and female dentists $\left(p=0.035^{*}\right)$. Compromising working postures with repeated movements and application of forces leading to fatigue of muscles of the upper extremities can result in WRMSDs among dental professionals. ${ }^{23}$ Explanations for the increased rate of MSDs in females might include a more sensitive perception of pain as well as the influence of sociocultural, psychological and biological factors. ${ }^{24}$ The application of sound ergonomic principles to the design of dental clinics and dental equipment can radically change the practice of dentistry.

About $81.3 \%$ of all participants stated that they had never taken medical advice for musculoskeletal disorders. This can be assumed that dentists themselves take self-medication to reduce the pain. In this context, the question arises as to what therapy could be offered to alleviate musculoskeletal pain and whether the intake of Non-steroidal anti-inflammatory drugs (NSAIDs) is useful. The possibility of answering affirmatively or acquiescence bias, deviation or faking bad bias, and social-desirability bias, should be considered as limitations of this study. Because the current study was a questionnaire-based and crosssectional design, might limit the generalizability of the study results.

\section{CONCLUSION}

The present findings conclude that knowledge concerning dental ergonomics has constantly increased. However, the results of the present study confirm that work-related MSDs prevalence is especially high in female dentists and has remained the same for the past two decades. It is recommended that different aspects of theoretical and practical ergonomics are included in the dental curriculum. Protective behavior like attending ergonomic training, relaxing training, or learning about coping strategies must be implemented to reduce stress at work and after work. Education related to ergonomic principles at an institutional level and in continuing dental programs plays a vital role in improving the quality of dental professional life. Emerging trends related to these musculoskeletal disorders call for a need to concentrate more on ergonomic awareness and practices in clinical dentistry. The Dental Council of India and syllabus regulatory bodies of health universities should devise ways to include ergonomics as a part of the syllabus, both theoretically and practically.

\section{REFERENCES}

1. Diaz-Caballero AJ, Gómez-Palencia IP. Ergonomic factors that cause the presence of pain muscle in students of dentistry. Med Oral Patol Oral Cir Bucal. 2010;15: 906e11.

2. Gupta S. Ergonomic applications to dental practice. Indian J Dent Res. 2011; 22: 816-22.

3. Freire AC, Soares GB, Rovida TA, Garbin CA, Garbin AJ. Musculoskeletal disorders and disability in Brazilian Dentists in São Paulo. Revista Dor. 2017;18(2):97-102. 
4. Zakaria D, Robertson J, MacDermid J, Hartford K, Koval J. Work-related cumulative trauma disorders of the upper extremity: Navigating the epidemiologic literature. Am J Ind Med. 2002; 42(3): 258-69.

5. Batra H, Rajvanshi H, Anshul K, Singh I, Chhabra N, Teja SV. An Estimation of Awareness among Practicing Dentists about Proper Ergonomic Practice and its Implications in Delhi - National Capital Region. Int J Sci Stud. 2015; 3(7):70-75.

6. Anu V, Babu AMS, Kumar PDM. Insights about Dental Ergonomics among Dental Students: The Need of the Hour to Recommend Dental Ergonomics in Academic Curriculum. Journal of Advanced Oral Research. 2018; 9(1-2): 49-54.

7. Lietz J, Kozak A, Nienhaus A. Prevalence and occupational risk factors of musculoskeletal diseases and pain among dental professionals in Western countries: A systematic literature review and metaanalysis. PLoS One. 2018;13(12):e0208628.

8. Leggat PA, Kedjarune U, Smith DR. Occupational health problems in modern dentistry. Ind Health, 2007; 45:611-21.

9. Shaik AR. Dental ergonomics: Basic steps to enhance work efficiency. Arch Med Health Sci. 2015; 3(1):138-44.

10. Karibasappa GN, Anandan S, Rajeshwari K. Dentists' knowledge, attitude and behavior towards the dental ergonomics. IOSR J Dent Med Sci. 2014;13: 86-9.

11. Hayes M, Cockrell D, Smith DR. A systematic review of musculoskeletal disorders among dental professionals. Int J Dent Hyg. 2009;7:159-65.

12. Kalghatgi S, Prasad KVV, Chhabra KG, Deolia S, Chhabra C. Insights into Ergonomics Among Dental Professionals of a Dental Institute and Private Practitioners in Hubli-Dharwad Twin Cities, India. Safety and health at work. 2014;5(4):181-5.

13. Alexopoulos EC, Stathi IC, Charizani F. Prevalence of musculoskeletal disorders in dentists. BMC Musculoskelet Disord. 2004;5(1):16.

14. Garbin AJ, Garbin CA, Diniz DG, Yarid SD. Dental students' knowledge of ergonomic postural requirements and their application during clinical care. Eur J Dent Educ. 2011; 15(1):31-5.
15. Vyas K, Parihar L, Rajoria K, Arora J, Pandit A, Singh J. Knowledge, attitude and behavior towards "ERGONOMICS" among oral health professionals in jodhpur city, Rajasthan, India. IJ Pre Clin Dent Res. 2014;1(3):5-9.

16. Almosa NA, Zafar $H$. Assessment of Knowledge about Dental Ergonomics among Dental Students of King Saud University, Riyadh, Kingdom of Saudi Arabia. J Contemp Dent Pract. 2019;20(3):324-9.

17. Khan SA, Chew KY. Effect of working characteristics and taught ergonomics on the prevalence of Musculoskelet Disord amongst dental students. BMC Musculoskelet Disord. 2013; 14(1):118.

18. Valachi B, Valachi K. Mechanisms leading to musculoskeletal disorders in dentistry. The Journal of the American Dental Association. 2003;134(10):13441350.

19. Ohlendorf D, Naser A, Haas Y, Haenel J, Fraeulin L, Holzgreve F, et al. Prevalence of Musculoskeletal Disorders among Dentists and Dental Students in Germany. Int. J. Environ. Res. Public Health. 2020; 17: 8740

20. Morse T, Bruneau H, Michalak-Turcotte C, Sanders M, Warren N, Dussetschleger J, et al. Musculoskeletal disorders of the neck and shoulder in dental hygienists and dental hygiene students. American Dental Hygienists' Association. 2007;81(1):10.

21. Zafar $\mathrm{H}$, Almosa N. Prevalence of Work-related Musculoskeletal Disorders among Dental Students of King Saud University, Riyadh, Kingdom of Saudi Arabia. J Contemp Dent Pract. 2019;20(4):449-53.

22. Hanefioglu M, Korhan $O$. Ergonomic Analysis of Dental Treatments Tasks: Discomfort Factor Identification And Impact On Body Regions. The Journal of Engineering and Architecture Faculty of Eskisehir Osmangazi University. 2018; 26(2): 47-67

23. Diaz-Caballero AJ, Gómez-Palencia I, Díaz-Cárdenas S. Ergonomic factors that cause the presence of pain muscle in students of dentistry. Medicina Oral, Patologia Oral y Cirugia Bucal. 2010; 15(6):e906.

24. Hallin RG. Pain more painful in women. Gender perspective neglected in research on the biological mechanisms of pain. Lakartidningen. 2003; 100: 3738-41. 